\title{
Renal involvement in primary Sjögren's syndrome
}

\author{
AQ1 Rhys Evans ${ }^{1}$, Anselm Zdebik', Coziana Ciurtin ${ }^{2}$ and Stephen B. Walsh'
}

\section{Abstract}

5 SS is a prevalent and underdiagnosed systemic disease that primarily affects epithelial tissue. It may affect renal function either as epithelial disease causing tubulointerstitial nephritis or as an immune complex-mediated glomerulopathy. These lesions may cause a variety of clinical features, both overt and occult. The epithelial disease is mediated by B and T cells, notably the Th17 subtype. We review the prevalence of renal SS, its presentation, likely pathogenesis and treatment.

10 Key words: Sjögren's syndrome, tubulointerstitial nephritis, autoimmune epithelialitis, Th17 cells, B cells, distal renal tubular acidosis, Fanconi syndrome, autoantibodies, vasculitis, hypocomplementaemia.

- Renal disease in primary SS is often occult and needs to be specifically looked for.

- Renal disease in primary SS may be associated with serious morbidity and even mortality.

- Renal primary SS is mainly epithelial and is likely to be driven by the same processes as in other tissues.

\section{Introduction}

\$\$ A described by Henrik Sjögren in 1933, is a chronic inflammatory disorder characterized by lymphocytic infiltration of epithelial tissue in exocrine glands and extraglandular sites [1]. Lacrimal and salivary gland infiltration

25 results in the classic sicca syndrome of dry eyes and dry moutbin $190 \%$ of patients [2]. However, SS is a heterogeneous disease; extraglandular infiltration can threaten organ function and carries an excess mortality, mainly due to lymphoproliferative disease, which occurs in up

30 to $10 \%$ of patients [3]. It may occur alone (primary SSPSS) or in association with other autoimmune diseases (e.g. SLE)^

pSS has been called an autoimmune epithelialitis [4], an apt term sinç the lymphocytic infiltrate is centred on epi-

35 thelial cells in each organ that it affects. This includes glandular epithelial cells in the lacrimal anch salivary glands, tubular epithelial cells in the kidney, respiratory epithelia anchsubmucosal glands within the lung $\wedge$ and biliary epithelia in hepatobiliary disease [5h

40 It classically occurs in middle-aged women, but can occur in other groups [6]. It has been estimated to affect $0.05-2.23 \%$ of the adult population [7]. It may be

${ }^{1}$ UCL Centre for Nephrology, UCL Medical School, Rowland Hill Street and ${ }^{2}$ Department of Rheumatology, University College London Hospital, London, UK

Submitted 9 December 2014; revised version accepted 6 May 2015. Correspondence to: Stephen B. Walsh, UCL Centre for Nephrology, UCL Medical School, Rowland Hill Street, London NW3 2PF, UK. E-mail: stephen.walsh@ucl.ac.uk asymptomatic with the incidental discovery of autgantibodies [8] or it may present with the sicca complex, constitutional symptoms or other organ involvement [9]/

\section{Renal/plisease in pSS}

Renal involvement in pSS was first described in the 1960s with reports of the typical tubular defects [10-12]. These included biopsy series that highlighted tubulointerstitial inflammation as the most common renal lesion [13]. Renal involvement in pSS is the result of two distinct pathophysiological processes: epithelial disease with a predominantly mononuclear lymphocytic infiltration resulting in tubulointerstitial nephritis (TIN) (Fig. 1) and non-epithelial disease with a secondary immune א̧omplex $\not$ mediated process resulting in glomerulopathy

\section{Prevalence of renal disease in pSS}

Three major series of renal involvement in pSS come from Spain and Greece [2, 7, 14]. These retrospective studies looked for overt disease and identified renal involvement in $5 \%, 4.9 \%$ and $4.3 \%$ of patients, respectively $\wedge$

Ramos-Casals et al. [2] defined renal involvement as one of proteinuria $>0.5 \mathrm{~g} /$ day $\wedge$ active urinary sediment $\wedge$

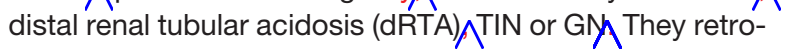
spectively applied this to a cohort of 1010 patients diagnosed with SS. $5 \%$ had evidence of renal involvement. In a cohort of 921 patients with pSS from the same group $4.3 \%$ had renal involvement at some stage [7]. 
FIG. 1 Slide of a haematoxylin and eosin-stained renal biopsy specimen demonstrating SS-related TIN

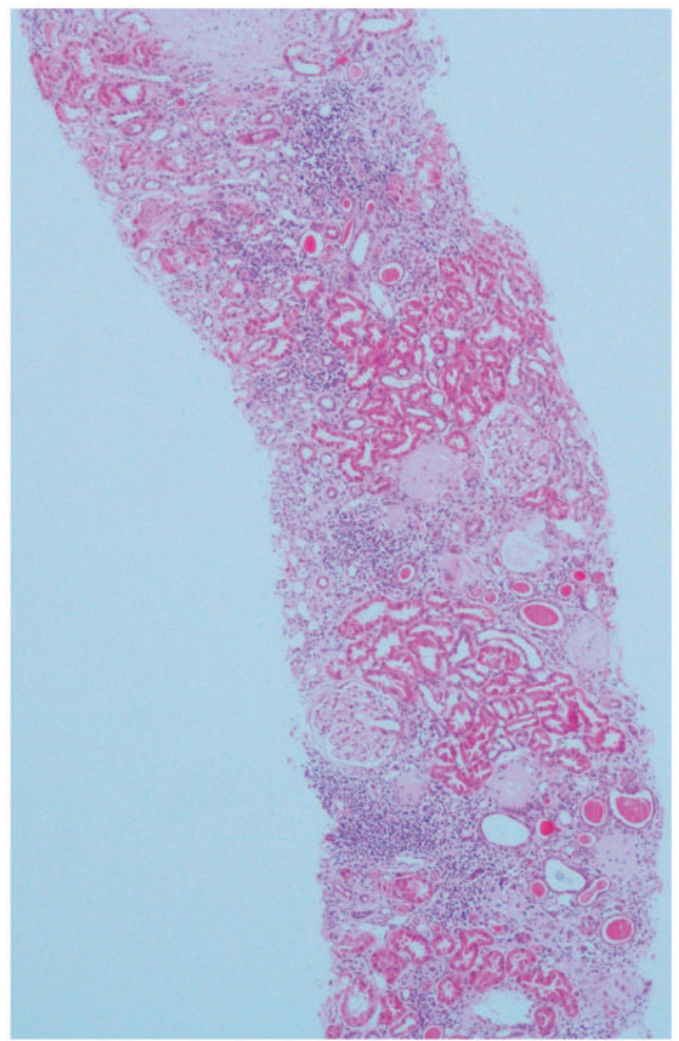

Areas with normal tubules are apparent, but localized foci of inflammatory cells have replaced these in other areas.

Goules et al. [14 1 defined renal involvement as one on low specific gravity $(<1.010)$ after water deprivation urinary $\mathrm{pH}>7$ for $>6$ months $\wedge$ renal colic with nephrolithiasis or nephrocalcinosis $\wedge$ Fanconi syndrome $\wedge$ impaired excre-

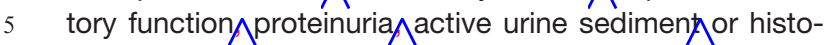
logical GN or TIN When retrospectively applied to a cohort of 715 patients, 35 had evidence of renal disease. A recent UK retrospective study of 152 pSS patients found that $10(6.5 \%)$ had renal involvement, defined by 10 the presence of renal tubular acidosis or GN [15]

However, in prospective studies of randomly selected pSS patients, specifically looking for tubular defects, the prevalence of renal involvement is much higher. The most recent studies estimate proximal injury to be present in

$1510-42 \%$, dRTA in 5-R4\% and a concentrating defect in 17-R8\% [16-19] (Table 1).

\section{Prevalence of different renal lesions}

Two large series with biopsy data confirm earlier reports that TIN is the predominant lesion, found in $\sim 75 \%$ of pa-

20 tients, with the remaining $\sim 25 \%$ of patients having glomerular disease $[20,21]$.

Maripuri et al. [21] reviewed all renal biopsies from a cohort of 7276 patients with pSS between 1967 and
2007 Twenty-foun renal biopsies were identified, $17(71 \%)$ of which had primarily TIN, while 7 (29\%) had glomerulopathy. Of these, $\wedge$ wo had co-existent mild TINA

Ren et al. [20] described a cohort of 130 pSS patients Forty-ong of these underwent biopsy, with $80 \%$ demonstrating TIN and 20\% glomerular disease. However, the Goules et al. [14] cohort did not show the same predominance of TIN; of the 33 biopsied patients, $52 \%$ had GN, $35 \%$ had TIN and $12 \%$ had both [14]

\section{Epithelial renal disease in pSS}

Histopathology of epithelial pSS

The predominant infiltrating cells are $\mathrm{CD} 4^{+} \mathrm{T}$ cells in both humans and mouse models, with $C D 8^{+} T$ cells, $B$ cells and macrophages being less numerous [22-24]. $C D 8^{+} T$ cells were the predominant cell that was responsible for tubular invasion in one series [24]. These findings are remarkably similar to those in other affected epithelia.

Much of the data on lymphocytic infiltration of epithelial tissue in pSS has come from labial salivary glandq (reviewed by Tzioufas et al. [25]). In salivary glands, the type of infiltrate varies $[26,27]$ and it has been suggested that specific therapies could be employed dependent on the predominant cell subtype found at the presenting biopsy [28]. Whether the histological severity or the predominant cell subtype correlate with patient outcome is unclear. While infiltration at extraglandular sites often coincides with glandular epithelial infiltration, whether one can use salivary gland histology to assess the severity of renal disease is not known $\wedge$

$T$ cells

$\mathrm{CD} 4^{+}$cells make up the bulk of the T cells present in labial salivary glands and there is evidence for a role of both Th1 and Th2 subtypes. Katsifis et al. [29] demonstrated increased levels of the cytokines required for Th17 proliferation (IL-6, IL-23 and TGF- $\beta$ ) and the predominant cytokine produced by Th17 cells (IL-17) in both the serum and salivary glands of pSS patients [29]. Indeed, IL-17 levels seemed to correlate with the severity of the histological lesion. Furthermore, in a mouse model of pSS, knocking out IL-17 prevents development of the disease [30]/

IL-22, a cytokine produced by Th17 cells $/$ has $/$ increased expression in salivary gland biopsies of pSS, and Th17 cells are the predominant source [31]. It was recently demonstrated that increased IL-17 in the salivary glands of pSS patients was from both $\mathrm{CD} 4^{+} \mathrm{T}$ cells and mast cells. After treatment with rituximab (RTX), tissue expression of IL-17 plecreased, but this was associated with a reduction in mast cell numberg ${ }^{r a t h e r}$ than $\mathrm{CD}^{+} \mathrm{T}$ cells

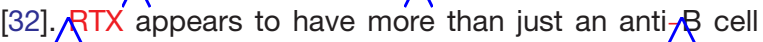
effect; similar modulation of the Th17 response by RTX has been shown in the setting of RA [33].

$B$ cells

Evidence for an important rolepf B cells in pSS includega high prevalence of autoantibodies, hypergammaglobulinaemia, increased risk of lymphoma, germinal centre 


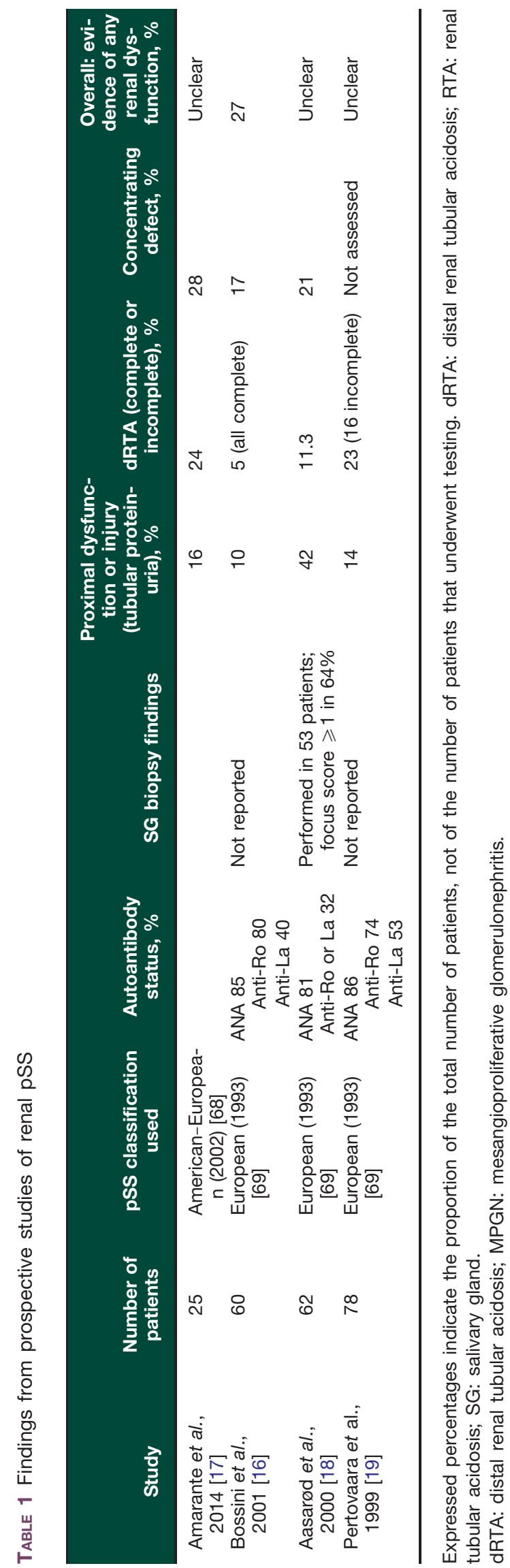

formation on histology and $x$ esponse of the disease to anti $\beta \beta$ cell therapy.

A range of different autoantibodies are seen in pSS patients. Some are disease markers, some are associated with specific clinical phenotypes and some may have a pathogenic role [34]/

Tubular defects

TIN may cause different defects in tubular function (Table 2)

\section{Distal renal tubular acidosis}

ARTA is due to inadequate $\mathrm{H}^{+}$secretion in the cortical collecting duct by the acid/secreting $\alpha$ jintercalated cells dRTA may be complete, with systemic metabolic acidosis and inappropriately alkaline urine, or incomplete, where the acidification defect is insufficient to causepvert acidosis; this can be revealed by dynamic testing. Testing can be through administration of either ammonium chloride [35] or furosemide and fludrocortisone [36]

dRTA causes urinary $\mathrm{K}^{+}$wasting. Patients may present with hypokalaemic symptoms, including paralysis [37]. Seven per cent of patients in one series presented with hypokalaemic paralysis and one patient had a cardiac arrest [20]. ARTA may also manifest as nephrolithiasis or nephrocalcinosis (Fig. 2), causing renal colic or urosepsis.

In prospective studies designed to look for dRTA in pSS, it is relatively common, in between $5 \%$ and $23 \%$ of patients $[16,18,19]$; its presence is associated with antiRo and La antibodies, longer disease duration, xerostomia, hypertension, אigher creatinine and proteinuria. Hypergammaglobulinaemia is also associated with dRTA in pSS [19]. In cohorts of known renal pSS, dRTA is even more common; as high as $70 \%$ in one series [20].

We have previously shown that vacuolar $\mathrm{H}^{+}$-ATPase and anion exchanger 1, transporters crucial to ajintercalated celyfunction, are undetectable on immunohistochemistry in pSS dRTA [38] Aptoantibodies to these proteins have been demonstrated in patients with pSS dRTA [39], but not consistently [40]. Congenital carbonic anhydrase II (CA II) deficiency also results in dRTA. Autoantibodies to CA II are associated with pSS, especially dRTA. Mice immunized with CA II develop a sialadenitis similar to pSS and a proportion of these mice had TIN [41]. Takemoto et al. [42] screened 46 patients with pSS, 13 of whom had dRTA Compared with controls, autoantibodies to CA II were increased in the pSS cohort and highest in those with dRTA. The same group subsequently immunized mice with CA II. CA II antibodies were associated with the development of a mild TIN in $\lceil 0 \%$ and dRTA on ammonium chloride testing [43]. Supportive management of dRTA includes supplementation of bicarbonate and potassium (e.g. oral potassium citrate) and close nephro-urological follow $\mu$ p to prevent complications from nephrolithiasis.

Nephrogenic diabetes insipidus

The initial reports of tubular dysfunction in pSS were of nephrogenic diabetes insipidus (NDI) [10, 11]; it is caused by dysfunction of the principal cells of the collecting duct. 
TABLE 2 A summary of the different clinical features associated with the different lesions of renal pSS

\begin{tabular}{|c|c|c|}
\hline & Mechanism & Presentation \\
\hline \multicolumn{3}{|l|}{$\begin{array}{l}\text { Epithelial disease-secondary to } \\
\text { lymphocytic infiltration }\end{array}$} \\
\hline \multirow[t]{2}{*}{$\begin{array}{l}\text { Cortical collecting duct dysfunc- } \\
\text { tion ( } \alpha \text {-intercalated cells) }\end{array}$} & dRTA: hypokalaemia & $\begin{array}{l}\text { Asymptomatic (routine blood tests) } \\
\text { Paralysis }\end{array}$ \\
\hline & $\begin{array}{l}\text { dRTA: nephrolithiasis/nephrocalcinosis, } \\
\text { hypercalciuria, hyperphosphaturia, } \\
\text { hypocitraturia }\end{array}$ & $\begin{array}{l}\text { Asymptomatic (imaging for other } \\
\text { indication) } \\
\text { Stones, nephrocalcinosis }\end{array}$ \\
\hline $\begin{array}{l}\text { Cortical collecting duct dysfunc- } \\
\text { tion (principal cells) }\end{array}$ & Concentrating defect & Polydipsia, polyuria, nocturia \\
\hline \multirow[t]{4}{*}{ Proximal tubular dysfunction } & Phosphaturia & Asymptomatic (routine blood tests) \\
\hline & Proximal renal tubular acidosis & Osteomalacia \\
\hline & & Stones, nephrocalcinosis \\
\hline & $\begin{array}{l}\text { Glycosuria } \\
\text { Low molecular weight proteinuria }\end{array}$ & Asymptomatic (routine urinalysis) \\
\hline $\begin{array}{l}\text { Loop of Henle and distal convo- } \\
\text { luted tubule dysfunction }\end{array}$ & Salt loss & $\begin{array}{l}\text { Asymptomatic (routine bloods or } \\
\text { urinalysis) }\end{array}$ \\
\hline (acquired Gitelman or Bartter & Hypokalaemia alkalosis & Non-specific \\
\hline syndrome) & $\begin{array}{l}\text { Hypomagnesaemia (more common with } \\
\text { Gitelman phenotype) } \\
\text { Hypocalciuria (Gitelman phenotype only) }\end{array}$ & Hypovolaemia and hypotension \\
\hline \multicolumn{3}{|l|}{$\begin{array}{l}\text { Non-epithelial disease-secondary } \\
\text { to immune complexes }\end{array}$} \\
\hline \multirow[t]{5}{*}{ Glomerular disease and vasculitis } & Glomerular disease & $\begin{array}{l}\text { Asymptomatic urinary abnormalities } \\
\text { Nephrotic syndrome } \\
\text { Hypertension } \\
\text { Reduced excretory function }\end{array}$ \\
\hline & Systemic vasculitis (cryoglobulinaemia) & $\begin{array}{l}\text { Systemic upset } \\
\text { Fevers }\end{array}$ \\
\hline & & Purpura \\
\hline & & Neuropathy \\
\hline & & Glomerular disease (MPGN) \\
\hline \multicolumn{3}{|l|}{$\begin{array}{l}\text { Both epithelial and non-epithelial } \\
\text { disease }\end{array}$} \\
\hline Decreased excretory function & & Asymptomatic (routine blood tests) \\
\hline
\end{tabular}

dRTA: distal renal tubular acidosis; MPGN: mesangioproliferative glomerulonephritis.

Presentation is with polydipsia, polyuria and nocturia. It may only be apparent on specific testing with the water deprivation test. It is as prevalent in the general pSS population as dRTA, being present in $17, \ldots 2 \%$ of patients (Table 5 1). $\wedge$ biopsy proven TIN it is present in $75 \%$ of patients, with only a quarten of these patients being symptomatic [14]. It was even more prevalent in those in which it was tested in Ren et al.'s [20] cohort, with 51/60 (85\%) patients having evidence of abnormal urinary concentrationXNDI in

10 pSS is a disease of adulthood, and the thirst mechanism is almost always robust enough to maintain the serum sodium within the normal range [44], thugspecific therapies for NDI (e.g. NSAIDs, diuretics) are not warranted.

\section{Proximal tubular dysfunction}

15 Proximal tubular cells (PTCg) are responsible for the reabsorption of most filtered electrolytes as well as low molecular weight (tubular) proteins, amino acids, glucose and urate. Together, tubular proteinuria, aminoaciduria, glycosuria, phosphaturia, uricosuriz and bicarbonaturia 20 comprise the Fanconi syndrome of peneralized PTG dysfunction. This may lead to osteomalacia as a consequence of phosphate wasting.

The full Fanconi syndrome is rare in pSS TIN (3\% [20]), but evidence of PTGdysfunction is much more common. The most sensitive marker, tubular proteinuria (e.g. retinol binding protein), is present in $10-42 \%$ in the general pSS series and up to $87 \%$ of those with known renal disease (Table 1)^

Other acquired tubular defects

There are case reports of pSS affecting other tubular segments, causing acquired Bartter or Gitelman-like syndromes [45-49]. Intriguingly, one of these cases was reported to have an autoantibody to the $\mathrm{NaCl}$ co-transporter (NCC) [48], the transporter affected by Gitelman syndrome.

\section{Non-epithelial renal disease in pSS}

\section{Histopathology of pSS GM}

The majority of glomerular disease reported in pSS is immune fomplex-pmediated, usually the characteristic 
FIG. 2 A plain abdominal X-ray showing bilateral nephrocalcinosis in a patient with SS-related TIN and distal renal tubular acidosis

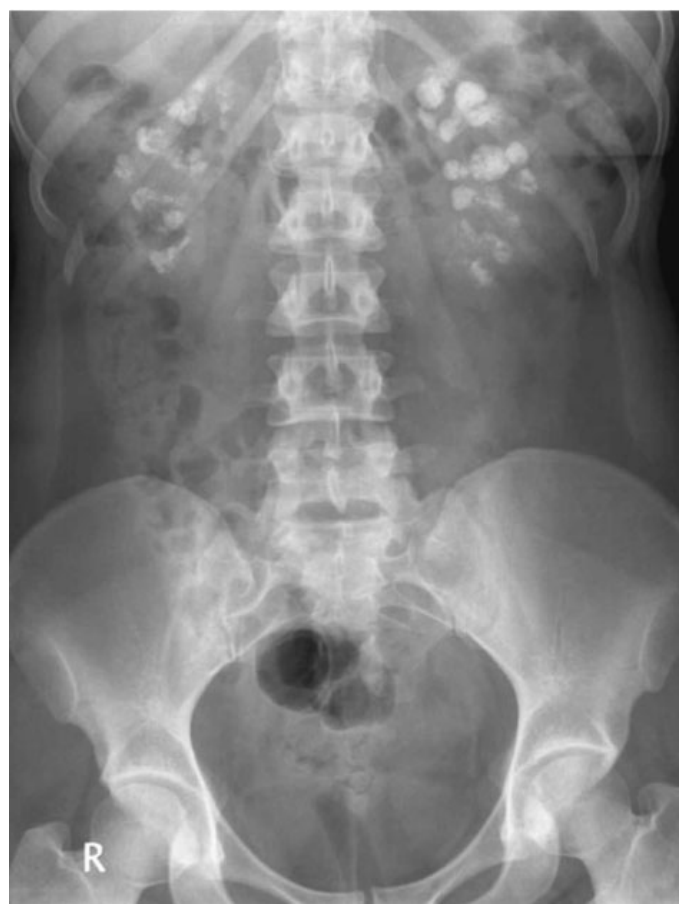

mesangioproliferative glomerulonephritis (MPGN), which is the most commonglomerular lesion in pSS. MPGN is caused by the deposition of immune complexes, which are often cryoglobulins; $64 \%$ of all patients with GN 5 were cryoglobulinaemic in the Goules et al. series [14]

Cryoglobulins are the result of $B$ cell expansion causing the synthesis of $\operatorname{lgM}$, which binds antigen and IgG. These immune complexes bind to endothelial cells, activate complement and recruit inflammatory cells, causing

10 small vessel vasculitis. In the kidney this manifests as MPGN, either alone or as part of a systemic vasculitis.

GN in pSS occurs later in the disease course than TIN. It is also associated with lymphoma development and thus increased morbidity and mortality [14, 50].

15 Glomerulopathy presents with typical glomerular features including haematuria, proteinuria, hypertension, reduced glomerular filtration rate and nephrotic syndrome (Table 2). There are various patterns of GN involvement described in SS (supplementary Table S1, available at

20 Rheumatology/pnline).

\section{Decreased excretory function}

Decreased excretory function is present in a relatively small proportion of those with renal involvement in pSS, being present in $27-31 \%$ in the larger series [14, 20]

25 (supplementary Table S2, available at Rheumatology Pnline). It can occur in those with either interstitial on glomerular disease. In the Goules et al. cohort, 54\% of those with TIN had reduced excretory function compared with $12 \%$ in those with glomerular disease. It was suggested that this may reflect the clinically silent 30 and therefore possibly untreategh nature of interstitial disease $\wedge$

If present, renal impairment in pSS TIN tends to be mild to moderate. However, progressive renal disease can occur, and rates as high as $12 \%$ of patients with renal pSS requiring dialysis have been reported [14 $/$ A

\section{Screening}

Given the multiple renal lesions that can occur with pSS and the relative difficulty in $x$ ecognizing them, we have compiled a guideline for physicians reating pSS patients to help screen for pSS passociated disease and refer the patient to nephrology services if appropriate (supplementary data, guide to screening for renal involvement in pSPa. available at Rheumatology (Pnline). We have deliberately avoided specialist renal investigationg ${ }$ so that screening these patients is feasible in the general clinic setting. These guidelines represent our opinion only and are not based on empirical evidence.

\section{Management}

No systemic immunosuppressive treatment is of proven benefit in pSS and treatment is largely based on extrapolations from treatment of other inflammatory conditions (e.g. SLE) and small open-label studies. Some randomized studies have been undertaken, but with negative or conflicting results [51-55]

While $\mathrm{ACQ}$ or MTX is the mainstay of uncomplicated pSS, steroids, $\mathcal{K Y C}$, anti-proliferative agents, calcineurin inhibitors and biologigagents (e.g. RTX) have been used to manage resistant or extraglandular disease $[56,57] . \lambda n$ addition to a lack of evidence for treatment of extraglandular pSS, there are no randomized studies on the management of pSS TIN, with treatment based on retrospective data of TIN treatment, again with conflicting results [58, 59]

TIN

In Maripuri et al.'s cohort [21], 88\% were treated with steroids $\AA$ and $53 \%$ had additional immunosuppression. The majority had stable renal function; only $18 \%$ had progressive renal disease Ren et al. [20] did not distinguish between glomerular and interstitial disease when discussing treatment, but the majority of the cohort had interstitial disease and were treated with immunosuppression (largely steroids aloneh The Greek group gave supportive treatment but not immunosuppression to those with interstitial disease $/$ [14].

We treat acute TIN with MMF and a weaning course of steroids $\wedge$ reserving B $\wedge$ cell-plepleting therapy for resistant disease. The clinical benefit of this strategy and how long it should be continued is the focus of current study $\mathrm{A}$

\section{GN}

Treatment of glomerular disease is based on the histological lesion. Within the renal cohorts described there is no consistent treatment of any of the glomerular disease (supplementary Table S3, available at Rheumatology 
Pnline). Most patients were treated with steroids with or without an additional immunosuppressant or plasma exchange. The limited outcome data suggest a reasonable response to any form of immunosuppression. For 5 example, there was no deterioration in function in any of the patients with glomerular involvement treated with immunosuppression in Maripuri et al.'s cohort [21]

Studies of non-infectious cryoglobulinaemic vasculitis include large numbers of pSS patients. The Cryoyes

10 study included 242 cases of non-infectious vasculitis, $25 \%$ of which were due to pSS [60]. In this retrospective cohort, treatment with RTX and corticosteroids was superior $\$$ e either corticosteroids alone or corticosteroids in combination with an alkylating agent. We therefore

15 favour a steroid and RTX regimen for cryoglobulinaemic vasculitis in the setting of pSS. We reserve plasma exchange for rapidly progressive glomerular or lifethreatening disease.

There has been much interest in the use of RTX in pSS

20 in the light of pur understanding of the important role $B$ cells play in disease pathogenesis, but also because of the effect RTX has on T cells, in particular modulation of the Th17 response [33]. The majority of recent randomized data in pSS concerns RTX use. Several open $>$ abel studies 25 demonstrating a positive effect of using RTX in pSS led to Nwo recent randomized controlled trials (RCTs) [61, 62]. These used improvements in either sicca symptoms or fatigue scores as primary outcomes, with conflicting

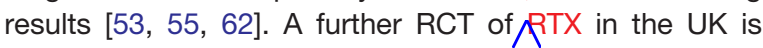
30 under way [63]. We can gain limited information on renal pSS from these trials, but it was interesting to note that five of ix patients with renal involvement in recent registry data from France improved with/PTX treatment [64]. Other biologig treatments may offer new avenues for the treat35 ment of pSS TINA

pSS patients may have increased levels of $\beta /$ fell activating facton [65], especially those with lymphoma. Belimumab, an anti- $\beta$ cell activating facto $\wedge$ antibody, has been trialled successfully in phase 2 studies in pSS [66],

40 improving symptom scores.

As Th17 cells appear to have an important role in epithelial inflammation in pSS, gecukinumab, an antiIL17 antibody, may have a role in the treatment of pSS, including renal SSAFurthermore, apatacept is another 45 potential therapy for renal pSS; a recent study showed that it improved salivary histology and saliva production in pSS [67].

\section{Conclusion}

Renal pSS is an underdiagnosed problem that can pre50 sent in a variety of different and covert ways. The pathogenesis of the pSS TIN lesion is likely to be the same as other epithelial lesions in pSS, and $\bar{\nearrow}$ cell responses appear to be important in this. Whether pSS TIN can provide insights into other forms of TIN (e.g. drug/felated TIN)

55 or even acute transplant rejection remains to be seen There is clearly much to be learned from this fascinating interaction of the immune system and the secretory epithelium.
Funding: No specific funding was received from any funding bodies in the public, commercial or not-for-profit sectors to carry out the work described in this/prticle.

Disclosure statement. Nhe authors have declared no conflicts of interest.

\section{Supplementary data}

Supplementary data are available at Rheumatology Online.

\section{References}

1 Sjögren H. Zur Kenntnis Der Keratoconjunctivitis Sicca li. Acta Ophthalmol 1935;13:1-39.

2 Ramos-Casals M, Solans R, Rosas $\mathrm{J}$ et al. Primary Sjögren syndrome in Spain: clinical and immunologic expression in 1010 patients. Medicine 2008;87:210-9.

3 Ioannidis JPA, Vassiliou VA, Moutsopoulos HM. Longterm risk of mortality and lymphoproliferative disease and predictive classification of primary Sjögren's syndrome. Arthritis Rheum 2002;46:741-7.

4 Moutsopoulos HM. Sjögren's syndrome: autoimmune epithelitis. Clin Immunol Immunopathol 1994;72:162-5.

5 Mitsias DI, Kapsogeorgou EK, Moutsopoulos HM. Sjögren's syndrome: why autoimmune epithelitis? Oral Dis 2006;12:523-32

6 Bogdanović R, Basta-Jovanović G, Putnik J, Stajić N, Paripović A. Renal involvement in primary Sjogren syndrome of childhood: case report and literature review. Mod Rheumatol 2013;23:182-9.

7 Ramos-Casals M, Brito-Zerón P, Solans R et al. Systemic involvement in primary Sjögren's syndrome evaluated by the EULAR-SS disease activity index: analysis of 921 Spanish patients (GEAS-SS Registry). Rheumatology 2014;53:321-31.

8 Jonsson R, Theander E, Sjöström B, Brokstad K, Henriksson G. Autoantibodies present before symptom onset in primary Sjögren syndrome. JAMA 2013;310:1854-5.

9 Ramos-Casals M, Brito-Zeron P, Siso-Almirall A, Bosch X. Primary Sjögren syndrome. BMJ 2012;344:e3821.

10 Khan M, Merritt AD, Wohl MJ, Orloff J. Renal concentrating defect in Sjögren's syndrome. Ann Intern Med 1962;56:883-95.

11 Shearn MA, Tu W-H. Nephrogenic diabetes insipidus and other defects of renal tubular function in Sjögren's syndrome. Am J Med 1965;39:312-8.

12 Tu WH, Shearn MA, Lee JC, Hopper J. Interstitial nephritis in Sjögren's syndrome. Ann Intern Med 1968;69:1163-70.

13 Talal N, Zisman E, Schur PH. Renal tubular acidosis, glomerulonephritis and immunologic factors in Sjogren's syndrome. Arthritis Rheum 1968;11:774-86.

14 Goules AV, Tatouli IP, Moutsopoulos HM, Tzioufas AG. Clinically significant renal involvement in primary Sjögren's syndrome: clinical presentation and outcome. Arthritis Rheum 2013;65:2945-53.

15 Abrol E, González-Pulido C, Praena-Fernández JM, Isenberg DA. A retrospective study of long-term outcomes 
in 152 patients with primary Sjögren's syndrome: 25-year experience. Clin Med 2014;14:157-64.

16 Bossini N, Savoldi S, Franceschini F et al. Clinical and morphological features of kidney involvement in primary Sjögren's syndrome. Nephrol Dial Transplant 2001;16:2328-36.

17 Amarante GBD, Zotin MC, Rocha E et al. Renal tubular dysfunction in patients with primary Sjögren syndrome. Clin Nephrol 2014;81:185-91.

1018 Aasarød K, Haga H-J, Berg KJ, Hammerstrøm J, Jørstad S. Renal involvement in primary Sjögren's syndrome. QJM 2000;93:297-304.

19 Pertovaara M, Korpela M, Kouri T, Pasternack A. The occurrence of renal involvement in primary Sjögren's syndrome: a study of 78 patients. Rheumatology 1999:38:1113-20.

20 Ren H, Wang W-M, Chen X-N et al. Renal involvement and followup of 130 patients with primary Sjögren's syndrome. J Rheumatol 2008;35:278-84.

2021 Maripuri S, Grande JP, Osborn TG et al. Renal Involvement in primary Sjögren's syndrome: a clinicopathologic study. Clin J Am Soc Nephrol 2009;4:1423-31.

22 Takada K, Takiguchi M, Konno A, Inaba M. Spontaneous development of multiple glandular and extraglandular lesions in aged IQI/Jic mice: a model for primary Sjögren's syndrome. Rheumatology 2004;43:858-62.

23 Rosenberg M, Schendel P, McCurdy FA et al. Characterization of immune cells in kidneys from patients with Sjogren's syndrome. Am J Kidney Dis 1988;11:20-2.

24 Matsumura R, Kondo $\mathrm{Y}$, Sugiyama T et al. Immunohistochemical identification of infiltrating mononuclear cells in tubulointerstitial nephritis associated with Sjogren's syndrome. Clin Nephrol 1988;30:335-40.

3525 Tzioufas AG, Kapsogeorgou EK, Moutsopoulos HM. Pathogenesis of Sjögren's syndrome: what we know and what we should learn. J Autoimmun 2012;39:4-8.

26 Kyriakidis NC, Kapsogeorgou EK, Tzioufas AG. A comprehensive review of autoantibodies in primary Sjögren's syndrome: clinical phenotypes and regulatory mechanisms. J Autoimmun 2014;51:67-74.

27 Kapsogeorgou EK, Christodoulou MI, Panagiotakos DB et al. Minor salivary gland inflammatory lesions in Sjögren syndrome: do they evolve? J Rheumatol 2013;40:1566-71

28 Mitsias DI, Tzioufas AG, Veiopoulou $\mathrm{C}$ et al. The Th1/Th2 cytokine balance changes with the progress of the immunopathological lesion of Sjogren's syndrome. Clin Exp Immunol 2002;128:562-8.

5029 Katsifis GE, Rekka S, Moutsopoulos NM, Pillemer S, Wah SM. Systemic and local interleukin-17 and linked cytokines associated with Sjögren's syndrome immunopathogenesis. Am J Pathol 2009;175:1167-77.

30 Lin X, Rui K, Deng J et al. Th17 cells play a critical role in the development of experimental Sjögren's syndrome. Ann Rheum Dis 2015;74:1302-10.

31 Ciccia F, Guggino G, Rizzo A et al. Potential involvement of IL-22 and IL-22-producing cells in the inflamed salivary glands of patients with Sjögren's syndrome. Ann Rheum
32 Ciccia F, Giardina A, Rizzo A et al. Rituximab modulates the expression of IL-22 in the salivary glands of patients with primary Sjogren's syndrome. Ann Rheum Dis 2013;72:782-3.

33 Van de Veerdonk FL, Lauwerys B, Marijnissen RJ et al. The anti-CD20 antibody rituximab reduces the Th17 cell response. Arthritis Rheum 2011;63:1507-16.

34 Tzioufas AG, Tatouli IP, Moutsopoulos HM. Autoantibodies in Sjögren's syndrome: clinical presentation and regulatory mechanisms. Presse Med 2012;41(9 Pt 2):e451-60.

35 Wrong O, Davies HEF. The excretion of acid in renal disease. QJM 1959;28:259-313.

36 Walsh SB, Shirley DG, Wrong OM, Unwin RJ. Urinary acidification assessed by simultaneous furosemide and fludrocortisone treatment: an alternative to ammonium chloride. Kidney Int 2007;71:1310-6.

37 Yılmaz H, Kaya M, Özbek M, Üreten K, Yıldıım is. Hypokalemic periodic paralysis in Sjögren's syndrome secondary to distal renal tubular acidosis. Rheumatol Int 2013;33:1879-82.

38 Walsh S, Turner CM, Toye A et al. Immunohistochemical comparison of a case of inherited distal renal tubular acidosis (with a unique AE1 mutation) with an acquired case secondary to autoimmune disease. Nephrol Dial Transplant 2007;22:807-12.

39 Bastani B, Haragsim L, Gluck S, Siamopoulos KC. Lack of H-ATPase in distal nephron causing hypokalaemic distal RTA in a patient with Sjögren's syndrome. Nephrol Dial Transplant 1995;10:908-9.

40 DeFranco PE, Haragsim L, Schmitz PG, Bastani B. Absence of vacuolar $\mathrm{H}(+)$-ATPase pump in the collecting duct of a patient with hypokalemic distal renal tubular acidosis and Sjögren's syndrome. J Am Soc Nephrol 1995;6:295-301.

41 Nishimori I, Bratanova T, Toshkov I et al. Induction of experimental autoimmune sialoadenitis by immunization of PL/J mice with carbonic anhydrase II. J Immunol 1995;154:4865-73.

42 Takemoto F, Hoshino J, Sawa N et al. Autoantibodies against carbonic anhydrase II are increased in renal tubular acidosis associated with Sjögren syndrome. Am J Med 2005;118:181-4

43 Takemoto F, Katori H, Sawa N et al. Induction of anticarbonic-anhydrase-II antibody causes renal tubular acidosis in a mouse model of Sjögren's syndrome. Nephron Physiol 2007;106:p63-8.

44 Khosravi M, Walsh SB. The long-term complications of the inherited tubulopathies: an adult perspective. Pediatr Nephrol 2015;30:385-95.

45 Higashi K, Kawaguchi Y, Suzuki K, Nakamura H. Sjögren's syndrome associated with hypokalemic myopathy due to Bartter's syndrome. J Rheumatol 1997;24:1663-4.

46 Pedro-Botet J, Tomas S, Soriano J, Coll J. Primary Sjögren's syndrome associated with Bartter's syndrome. Clin Exp Rheumatol 1990;9:210-2.

47 Hinschberger $\mathrm{O}$, Martzolff L, loannou G et al. Syndrome de Gitelman acquis au cours d'un syndrome de GougerotSjögren associé à une sclérodermie. Rev Med Intern 2011;32:e96-8. 
48 Kim YK, Song HC, Kim W-Y et al. Acquired Gitelman syndrome in a patient with primary Sjögren syndrome. Am $J$ Kidney Dis 2008;52:1163-7.

49 Chen Y-C, Yang W-C, Yang A-H et al. Primary Sjögren's syndrome associated with Gitelman's syndrome presenting with muscular paralysis. Am J Kidney Dis 2003;42:586-90.

50 Voulgarelis M, Skopouli FN. Clinical, immunologic, and molecular factors predicting lymphoma development in Sjögren's syndrome patients. Clin Rev Allergy Immunol 2007;32:265-74.

51 Mariette X, Ravaud P, Steinfeld S et al. Inefficacy of infliximab in primary Sjögren's syndrome: results of the randomized, controlled Trial of Remicade in Primary Sjögren's Syndrome (TRIPSS). Arthritis Rheum 2004;50:1270-6.

52 Zandbelt MM, Wilde P de, Damme P van et al. Etanercept in the treatment of patients with primary Sjögren's syndrome: a pilot study. J Rheumatol 2004;31:96-101.

2053 Dass S, Bowman SJ, Vital EM et al. Reduction of fatigue in Sjögren syndrome with rituximab: results of a randomised, double-blind, placebo-controlled pilot study. Ann Rheum Dis 2008;67:1541-4.

54 Devauchelle-Pensec V, Mariette X, Jousse-Joulin S et al. Treatment of primary Sjögren syndrome with rituximab: a randomized trial. Ann Intern Med 2014;160:233-42.

55 Meijer JM, Meiners PM, Vissink A et al. Effectiveness of rituximab treatment in primary Sjögren's syndrome: a randomized, double-blind, placebo-controlled trial. Arthritis Rheum 2010;62:960-8.

56 Brito-Zerón P, Sisó-Almirall A, Bové A, Kostov BA, Ramos-Casals M. Primary Sjögren syndrome: an update on current pharmacotherapy options and future directions. Expert Opin Pharmacother 2013;14:279-89.

3557 Ramos-Casals M, Brito-Zerón P, Sisó-Almirall A, Bosch X, Tzioufas AG. Topical and systemic medications for the treatment of primary Sjögren's syndrome. Nat Rev Rheumatol 2012;8:399-411.
58 González E, Gutiérrez E, Galeano C et al. Early steroid treatment improves the recovery of renal function in patients with drug-induced acute interstitial nephritis. Kidney Int 2008;73:940-6.

59 Clarkson MR, Giblin L, O'Connell FP et al. Acute interstitial nephritis: clinical features and response to corticosteroid therapy. Nephrol Dial Transplant 2004;19:2778-83.

60 Terrier B, Krastinova E, Marie I et al. Management of noninfectious mixed cryoglobulinemia vasculitis: data from 242 cases included in the CryoVas survey. Blood 2012;119:5996-6004.

61 Pijpe J, van Imhoff GW, Spijkervet FKL et al. Rituximab treatment in patients with primary Sjögren's syndrome: an open-label phase II study. Arthritis Rheum 2005;52:2740-50

62 Devauchelle-Pensec V, Pennec Y, Morvan J et al. Improvement of Sjögren's syndrome after two infusions of rituximab (anti-CD20). Arthritis Care Res 2007;57:310-7.

63 Brown S, Coy NN, Pitzalis C et al. The TRACTISS Protocol: a randomised double blind placebo controlled clinical TRial of Anti-B-Cell Therapy In patients with primary Sjögren's syndrome. BMC Musculoskelet Disord 2014;15:21.

64 Gottenberg J-E, Cinquetti G, Larroche C et al. Efficacy of rituximab in systemic manifestations of primary Sjögren's syndrome: results in 78 patients of the Autolmmune and Rituximab registry. Ann Rheum Dis 2013;72:1026-31.

65 Mariette X, Roux S, Zhang J et al. The level of BLyS (BAFF) correlates with the titre of autoantibodies in human Sjögren's syndrome. Ann Rheum Dis 2003;62:168-71.

66 Mariette X, Seror R, Quartuccio L et al. Efficacy and safety of belimumab in primary Sjögren's syndrome: results of the BELISS open-label phase II study. Ann Rheum Dis 2015;74:526-31.

67 Adler S, Körner M, Förger F et al. Evaluation of histologic, serologic, and clinical changes in response to abatacept treatment of primary Sjögren's syndrome: a pilot study. Arthritis Care Res 2013;65:1862-8. 


\title{
Author Query Form
}

\author{
Journal: Rheumatology \\ Article Doi: 10.1093/rheumatology/kev223 \\ Article Title: Renal involvement in primary Sjögren's syndrome \\ First Author: Rhys Evans \\ Corr. Author: Stephen B. Walsh
}

\section{AUTHOR QUERIES - TO BE ANSWERED BY THE CORRESPONDING AUTHOR}

The following queries have arisen during the typesetting of your manuscript. Please click on each query number and respond by indicating the change required within the text of the article. If no change is needed please add a note saying "No change."

AQ1: $\quad$ Please check that all names have been spelled correctly and appear in the correct order. Please also check that all initials are present. Please check that the author surnames (family name) have been correctly identified by a pink background. If this is incorrect, please identify the full surname of the relevant authors. Occasionally, the distinction between surnames and forenames can be ambiguous, and this is to ensure that the authors' full surnames and forenames are tagged correctly, for accurate indexing online. Please also check all author affiliations.

AQ2: Abbreviations from the standard Rheumatology list are used without definition http://www.oxfordjour nals.org/our_journals/brheum/for_authors/abbreviations_feb_2015.pdf

AQ3: $\quad$ Please check hierarchy of headings. 